\title{
Article \\ Effect of Substrate Misorientation on the Structural and Optical Characteristics of In-Rich InGaAs/GaAsP Quantum Wells
}

\author{
Zhiwei Li ${ }^{1,2}$, Yugang Zeng ${ }^{1,2, *}$, Yue Song ${ }^{1,2, *}$, Jianwei Zhang ${ }^{1,2}$, , Yinli Zhou 1,2, Yongqiang Ning ${ }^{1,2}$, Li Qin ${ }^{1,2}$ \\ and Lijun Wang 1,2
}

1 State Key Laboratory of Luminescence and Application, Changchun Institute of Optics, Fine Mechanics and Physics, Chinese Academy of Sciences, Changchun 130033, China; lizhiwei17@mails.ucas.ac.cn (Z.L.); zhouyinli@ciomp.ac.cn (Y.Z.); ningyq@ciomp.ac.cn (Y.N.); qinl@ciomp.ac.cn (L.Q.); wanglj@ciomp.ac.cn (L.W.)

2 Center of Materials Science and Optoelectronics Engineering, University of Chinese Academy of Sciences, Beijing 100049, China

* Correspondence: zengyg@ciomp.ac.cn (Y.Z.); songyue@ciomp.ac.cn (Y.S.); zjw1985@ciomp.ac.cn (J.Z.); Tel.: +86-138-4308-8351 (Y.Z.)

check for

Citation: Li, Z.; Zeng, Y.; Song, Y.; Zhang, J.; Zhou, Y.; Ning, Y.; Qin, L.; Wang, L. Effect of Substrate Misorientation on the Structural and Optical Characteristics of In-Rich InGaAs/GaAsP Quantum Wells. Appl. Sci. 2021, 11, 8639. https:// doi.org/10.3390/app11188639

Academic Editors: Giuseppe Rizzelli and John Xiupu Zhang

Received: 9 August 2021

Accepted: 12 September 2021

Published: 17 September 2021

Publisher's Note: MDPI stays neutral with regard to jurisdictional claims in published maps and institutional affiliations.

Copyright: (C) 2021 by the authors. Licensee MDPI, Basel, Switzerland. This article is an open access article distributed under the terms and conditions of the Creative Commons Attribution (CC BY) license (https:/ / creativecommons.org/licenses/by/ $4.0 /)$.

\begin{abstract}
InGaAs quantum well (QW) lasers have attracted significant attention owing to their considerable potential for applications in optical communications; however, the relationship between the misorientation of the substrates used to grow InGaAs QWs and the structural and optical properties of QWs is still ambiguous. In this study, In-rich InGaAs/GaAsP single QWs were grown in the same run via metal organic chemical vapor deposition on GaAs (001) substrates misoriented by $0^{\circ}$, $2^{\circ}$, and $15^{\circ}$ toward (111). The effects of substrate misorientation on the crystal quality and structural properties of InGaAs/GaAsP were investigated by X-ray diffraction and Raman spectroscopy. The $0^{\circ}$ substrate exhibited the least lattice relaxation, and with increasing misorientation, the degree of lattice relaxation increased. The optical properties of the InGaAs/GaAsP QWs were investigated using temperature-dependent photoluminescence. An abnormal S-shaped variation of the peak energy and inverse evolution of the spectral bandwidth were observed at low temperatures for the $2^{\circ}$ substrate, caused by the localization potentials due to the In-rich clusters. Surface morphology observations revealed that the growth mode varied with different miscuts. Based on the experimental results obtained in this study, a mechanism elucidating the effect of substrate miscuts on the structural and optical properties of QWs was proposed and verified.
\end{abstract}

Keywords: misorientation; optical communication; InGaAs/GaAsP quantum well; optical properties; localization potential

\section{Introduction}

Long wavelength semiconductor laser diodes have been an important technology in recent years, because of their major role in optical communications [1]. These lasers emit at wavelengths near the infrared band, and the InGaAs material system has shown promise as an active layer candidate for realizing wavelengths beyond $1 \mu \mathrm{m}$. Because the large lattice mismatch between InGaAs and GaAs substrates limits the layer thickness and heterointerface smoothness, several studies have been performed to improve the interface roughness and crystal quality. Nagle et al. improved the quality of the $\mathrm{GaAs} / \mathrm{InGaAs}$ interface using short annealing steps at various growth temperatures [2]. Ma et al. demonstrated the possibility of avoiding strain accumulation in InGaAs layers using a gas-switching technique during growth [3]. In order to achieve a longer excitation wavelength, it is necessary to increase the indium (In) content in InGaAs QWs. However, a high content of In tends to cause a significant lattice mismatch between the wells and barriers. Lattice-mismatched heteroepitaxy is always accompanied by the generation of strain and dislocations, which degrade the device performance [4]. In order to reduce or eliminate 
strain accumulation and the formation of defects in QWs, tensile-strain GaAsP barrier layers have been employed to compensate for the compressive strain in the InGaAs QW layer. Compressive strain in the well and tensile strain in the barrier can offset each other during epitaxial growth, which reduces the formation of defects, such as dislocations [5]. Therefore, radiative recombination and surface roughness can be improved. However, the precise strain-balanced condition is not straightforward, and the mismatch strain is unavoidable. The growth of high quality $\mathrm{InGaAs} / \mathrm{GaAsP} \mathrm{QWs}$ is vital for realizing high performance devices. Choi et al. found that a reduction in the growth temperature yielded highly strained epitaxial layers with decent optical properties presumably owing to the reduced formation and propagation of dislocations [6]. Hou et al. studied the influence of different compositions of phosphorus in the barrier layer on the production of a high quality and smooth heterointerface of InGaAs/GaAsP QWs [7]. Dong et al. investigated the influence of growth temperature on interfacial quality of InGaAs/GaAsP multiple quantum wells [8]. Therefore, the optimization of crystal growth conditions is crucial to facilitate the production of high-performance devices.

Substrate misorientation is known to be crucial for developing high-efficiency solar cells and high-performance QW diode lasers [9]. However, the correlation between the structural and optical properties of InGaAs QWs and GaAs substrates with different misorientation angles has not yet been thoroughly investigated. Lin et al. investigated the influence of a tilted substrate on the photoluminescence, mismatch, doping, thickness, and morphology of GaInP QWs and found that the $15^{\circ}$ substrate was a suitable choice for use in a red light waveband laser diode wafer [10]. Botha et al. studied the influence of growth interruption and substrate misorientation on the optical and heterointerface properties; the use of the growth interruption technique during growth resulted in the $2^{\circ}$ substrate being preferred for the growth of InGaAs/GaAs QWs [11]. They mainly explored the effect of epitaxial growth conditions on the structure of materials with little lattice mismatch on misoriented substrate. However, there are few studies about the effect of substrate misorientation on QWs with large lattice mismatch. The use of vicinal substrates for growing InGaAs/GaAsP QWs has become technologically significant because they result in improved optical properties [9]. However, the correlation between the structural and optical properties of In-rich InGaAs QWs and GaAs substrates with different misorientation angles has not been elucidated.

In this study, the dependence of structural and optical properties of large-mismatch InGaAs/GaAsP QWs on substrate misorientation were investigated and analyzed in detail. This provides a better experimental method and theoretical basis for the preparation of novel optoelectronic materials and devices.

\section{Materials and Methods}

In-rich InGaAs/GaAsP QWs were grown on n-type GaAs (001) substrates misoriented by $0^{\circ}, 2^{\circ}$, and $15^{\circ}$ toward (111) using a MOCVD AIXTRON 200/4 reactor under identical growth conditions. The following reactants were used: trimethylindium (TMIn), trimethylgallium (TMGa), arsine $\left(\mathrm{AsH}_{3}\right)$, and phosphine $\left(\mathrm{PH}_{3}\right)$. Purified $\mathrm{H}_{2}$ was used as a carrier gas. The growth pressure and temperature of the MOCVD system were set to $100 \mathrm{mbar}$ and $630{ }^{\circ} \mathrm{C}$, respectively, a growth rate of $0.5 \mathrm{~nm} / \mathrm{s}$ during the growth and $\mathrm{V} / \mathrm{III}$ ratios of 80 were employed. The structure of an InGaAs/GaAsP QW is depicted in Figure 1. For all three samples, the substrate surface was deoxidized via thermal desorption at $680^{\circ} \mathrm{C}$ for 5 min under an $\mathrm{AsH}_{3}$ atmosphere. A $300 \mathrm{~nm} \mathrm{GaAs}$ buffer layer was subsequently grown on the 2-inch oriented GaAs substrate using TMGa and $\mathrm{AsH}_{3}$ with a growth time of $\sim 600 \mathrm{~s}$. A $5 \mathrm{~nm}$ GaAsP barrier was subsequently grown, followed by the growth of a $7 \mathrm{~nm} \mathrm{InGaAs}$ QW. Finally, a $5 \mathrm{~nm} \mathrm{GaAsP}$ barrier with a $\mathrm{PH}_{3}: \mathrm{AsH}_{3}$ ratio of 3.5:1 in the vapor phase was employed as the capping layer. 


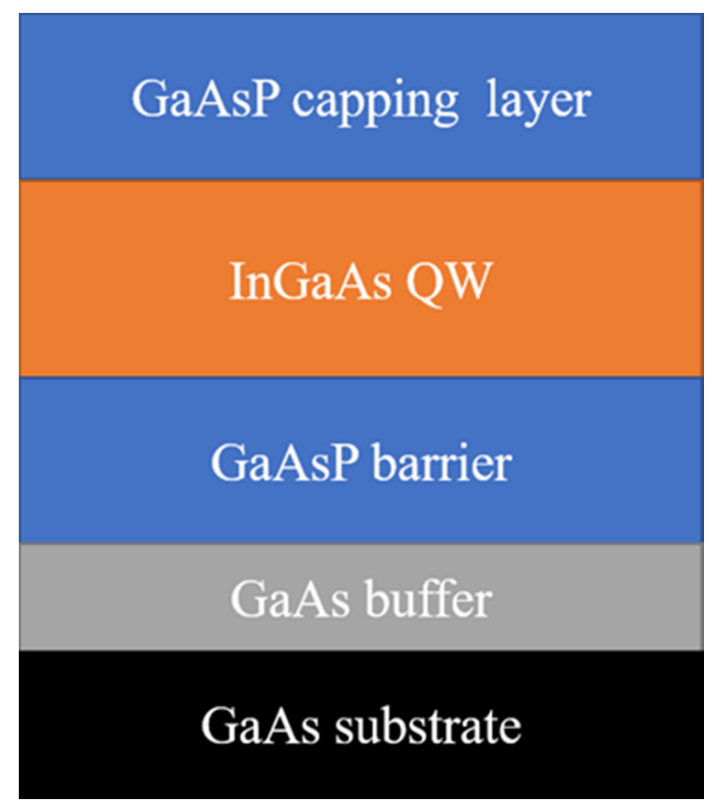

Figure 1. Schematic of the InGaAs/GaAsP quantum well.

To achieve lasing at near-infrared wavelength in this study, the In and phosphorous compositions were fixed at $38 \%$ and $20 \%$ in the InGaAs QWs and GaAsP barriers, respectively; the thicknesses of the QWs and barriers were estimated to be 7 and $5 \mathrm{~nm}$, respectively. Lattice constants are known to change with composition, and the effects of the composition of In on lattice constants can be expressed as follows:

$$
a_{\mathrm{In}_{x} \mathrm{GaAs}}=a_{\mathrm{GaAs}}+\left(a_{\mathrm{InAs}}-a_{\mathrm{GaAs}}\right) \cdot x .
$$

The strain in the layers can be defined as follows:

$$
\varepsilon=\frac{\Delta a}{a_{\text {sub }}}
$$

where $\Delta a$ is the difference between the lattice constants of the two materials and $a_{\text {sub }}$ is the lattice constant of the substrate. The lattice constant of $\operatorname{In}_{0.38} \mathrm{GaAs}$ is obtained as $5.807 \AA$ using Equation (1) and the compressive strain of the $\mathrm{In}_{0.38} \mathrm{Ga}_{0.62} \mathrm{As}$ layer is evaluated to be 27,224 ppm (Equation (2)). Tensile strain GaAsP barrier layers were employed to compensate for the compressive strain in the InGaAs QW layer, and then the defect density was reduced. The average strain is defined as [7]

$$
\left(T_{\mathrm{InGaAs}} \times \varepsilon_{\mathrm{InGaAs}}+T_{\mathrm{GaAs} P} \times \varepsilon_{\mathrm{GaAs} P}\right) /\left(T_{\mathrm{InGaAs}}+T_{\mathrm{GaAs} P}\right) .
$$

where $T$ and $\varepsilon$ represent the thickness and strain of each layer, respectively. $\varepsilon$ is positive if the layer has compressive strain and is negative for tensile strain. The accumulated strain in the InGaAs/GaAsP QW was 7006 ppm, which indicated that it was not fully compensated and residual strain was likely present in the material.

To investigate the crystal quality, and strain mismatch of the epitaxial layers, the samples were identified by X-ray diffraction (XRD, Bruker D8). A Raman spectrometer (RENISHAW InVia) was employed to study the structural disorder and residual strain in the epitaxial layers of the three samples. Atomic force microscopy (AFM, Bruker MultiMode 8) was used to conduct morphological analysis and determine the RMS surface roughness. The optical characteristics of the InGaAs/GaAsP QW were investigated using temperaturedependent photoluminescence spectroscopy (ARS 8200 cryogenic system) with a $488 \mathrm{~nm}$ continuous-wave laser. 


\section{Results and Discussion}

Figure 2 shows the XRD patterns of the InGaAs/GaAsP QWs with different miscut angles. The strongest peak originated from the GaAs substrates, and the satellite peaks of the $\mathrm{QW}$ are clearly visible in samples with miscut angles of $0^{\circ}$ and $2^{\circ}$. However, the satellite peaks of the InGaAs/GaAsP QW disappeared in the XRD pattern of the $15^{\circ}$ sample, which indicated its poor interfacial quality [12]. From the XRD patterns of the three samples in Figure 2, the relax are obtained by the simulation of the diffraction patterns, $5.03 \%$ strain relaxation occurs in the $0^{\circ}$ sample while $19.26 \%$ strain relaxes in the $2^{\circ}$ sample, as for the $15^{\circ}$ sample, $90.58 \%$ strain relaxation occurs [13]. The XRD result show that the crystal quality degraded with increasing the angle of substrate misorientation.

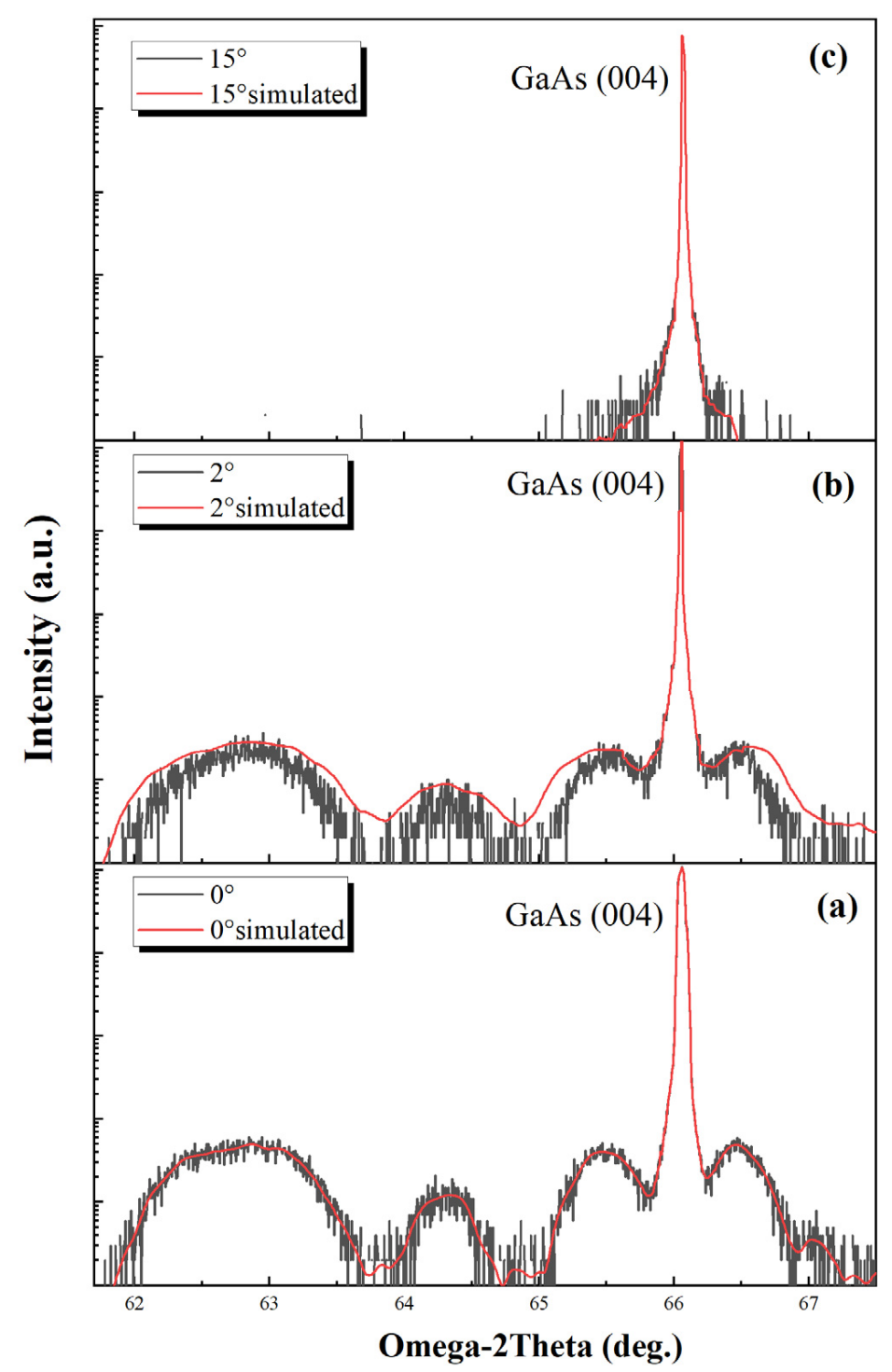

Figure 2. Omega-2 $\theta$ scans around the (004) symmetric XRD patterns of InGaAs/GaAsP QWs grown on substrates with misorientations of $(\mathbf{a}) 0^{\circ},(\mathbf{b}) 2^{\circ}$, and (c) $15^{\circ}$.

Raman scattering is an important technique used to investigate the optical properties of materials, wherein the disorder and local strain phenomena in materials can be adequately represented by vibrational spectra. The disorder and strain in materials can alter the phonon frequency and phonon lifetime, which can lead to the broadening of the Raman spectrum and breaking of Raman selection rules [14]. The frequency shifts of longitudinal optical (LO) phonons are extremely sensitive to strain; compressive and tensile strain are known to result in positive and negative frequency shifts, respectively [15]. 
The samples prepared in this study feature a lattice mismatch between the In-rich InGaAs $Q W$ and the GAs substrate. The In-rich layer generates a lattice mismatch stress in the adjacent epitaxial layer. The residual stress in the epitaxial layer can be obtained by measuring the frequency shift of the characteristic peak of GaAs via Raman scattering. The stress in the InGaAs material can be evaluated using the frequency shift of the GaAs-like LO mode of the InGaAs material; Equation (4) was utilized to calculate the frequency of the GaAs-like LO mode in the InGaAs epitaxial layer [16]:

$$
\omega_{L O}=290-18.6 x-32.5 x^{2},
$$

where $x$ is the content of In and $\omega_{L O}$ is the GaAs-like LO frequency in the strain-free InGaAs material as a function of $x$. The GaAs-like LO frequency in an ideal strain-free $\mathrm{In}_{0.38} \mathrm{Ga}_{0.62}$ As layer is evaluated to be $278.2 \mathrm{~cm}^{-1}$. The residual strain in the epitaxial layer is evaluated using the deviation from the measured frequency of the GaAs-like LO mode to that of the ideal strain-free $\mathrm{In}_{0 \cdot 38} \mathrm{Ga}_{0 \cdot 62}$ As layer [17].

GaAs-related LO phonons from InGaAs/GaAsP QWs are known to consist of two LO phonon modes [18]—one from the GaAs buffer layer because of the thin QW that can be penetrated into the GaAs buffer layer [19], and the other from the InGaAs layer that exhibits a GaAs-like LO phonon peak. As shown by the dashed line in Figure 3, the GaAs-like LO frequency in the ideal strain-free $\operatorname{In}_{0.38} \mathrm{Ga}_{0} \cdot{ }_{62}$ As epitaxial layer was obtained as $278.2 \mathrm{~cm}^{-1}$. The GaAs-like LO frequency of the $2^{\circ} \mathrm{GaAs}$ substrate was observed at $283.4 \mathrm{~cm}^{-1}$ via fitting of the Raman spectra; this sample features the smallest shift with respect to $278.2 \mathrm{~cm}^{-1}$ compared to that of the $0^{\circ}$ GaAs substrate $\left(285.2 \mathrm{~cm}^{-1}\right)$, which indicated that the strain induced via lattice mismatch was partially relaxed in the epitaxial layer in the $2^{\circ} \mathrm{GaAs}$ substrate. The GaAs-like LO frequency of the $15^{\circ} \mathrm{GaAs}$ substrate was observed at $279.8 \mathrm{~cm}^{-1}$ which is very close to the ideal strain-free $\mathrm{In}_{0.38} \mathrm{Ga}_{0.62} \mathrm{As}$ layer and indicated that substantial strain had relaxed in $15^{\circ}$ substrate.

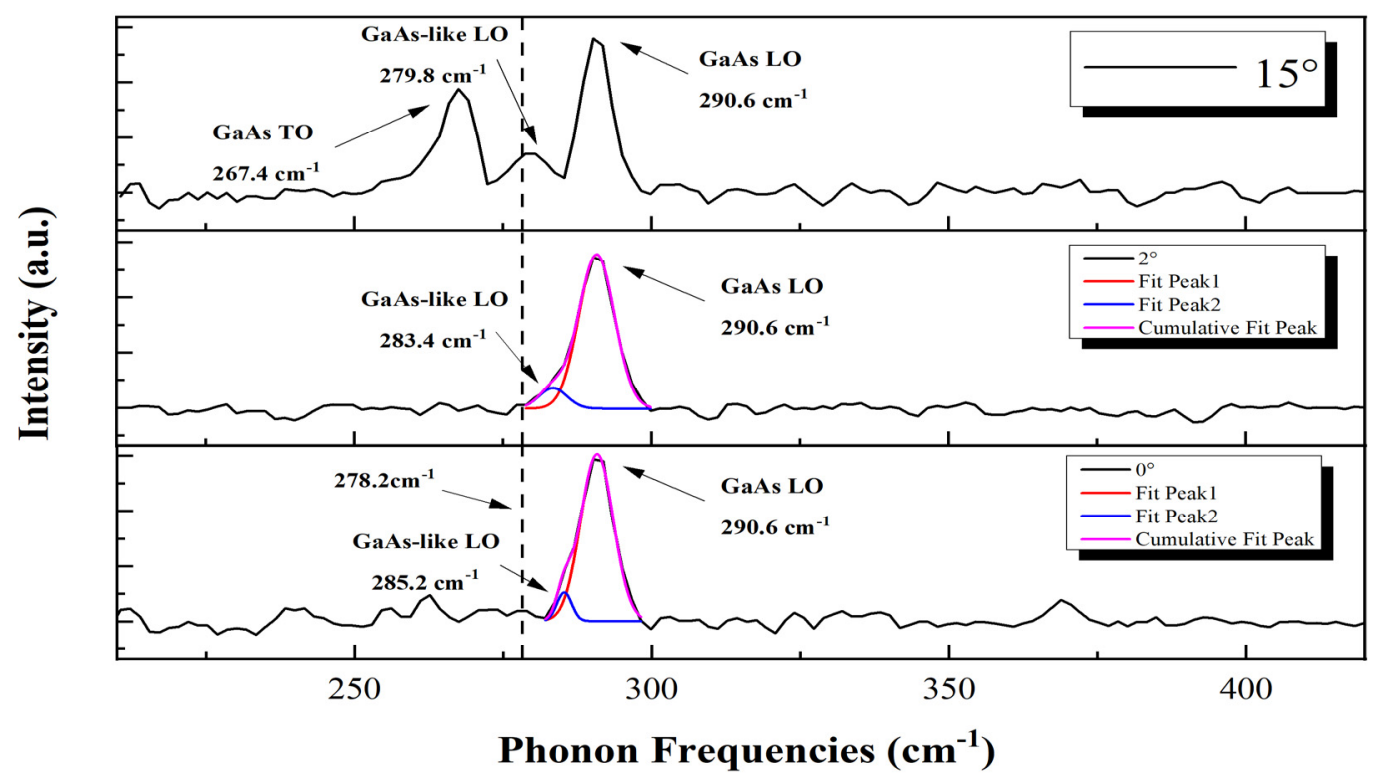

Figure 3. Raman spectra of InGaAs/GaAsP QWs grown on a GaAs (001) substrate with misorientations of $0^{\circ}, 2^{\circ}$, and $15^{\circ}$ using a $488 \mathrm{~nm}$ laser.

The full width at half maximum (FWHM) values of the GaAs-like LO frequencies for the $0^{\circ}$ and $2^{\circ}$ substrates were obtained as 3.0 and $5.6 \mathrm{~cm}^{-1}$, respectively, by fitting the Raman spectra. The increase in the FWHM of GaAs-like LO phonons suggests that the residual strains released through defect generation and structural disorder [15,20]. Consequently, the epitaxial layer on the $2^{\circ} \mathrm{GaAs}$ substrate exhibited a poorer crystalline quality than that of the $0^{\circ} \mathrm{GaAs}$ substrate. 
Raman selection rules are often applied for analyzing the crystal quality; the LO phonon is allowed and the TO phonon is forbidden for the (001) plane of a sphalerite crystal structure [21-24]. The disorder in InGaAs films can be assessed by the ratio between the TO and LO peak intensities because the presence of the TO phonon is an indicator of crystal structural disorder. As shown in Figure 3, the TO mode at $267.4 \mathrm{~cm}^{-1}$ appeared only in the $15^{\circ}$ sample, confirming its extremely large degree of crystal disorder compared to that of the other two samples [25]. The above results show that the strain relaxes gradually with the increase of the misorientation. These results follow trends similar to those observed in the $X R D$ results.

AFM analysis was subsequently conducted to verify the growth model of the InGaAs/GaAsP QWs. Figure 4 shows the AFM results on the surface morphologies of the three samples with different misorientations. Figure 4a reveals that the $0^{\circ}$ sample exhibited a step-flow characteristic with RMS surface roughness of $0.147 \mathrm{~nm}$, which indicated the high quality of the heterointerface in the $0^{\circ}$ sample. Figure $4 \mathrm{~b}$ indicated the narrowing of the terrace width in the $2^{\circ}$ sample; the RMS surface roughness increased from 0.147 to $0.363 \mathrm{~nm}$ due to the composition-related inhomogeneity of In clusters that lead to a partial internal strain relaxation. In this case, the localization potential was formed because of the In clusters. Figure $4 \mathrm{c}$ reveals the presence of self-assembled quasi-quantum dots in the $15^{\circ}$ sample. Randomly positioned growth nuclei were formed and the local strain subsequently relaxed at the locations of these nuclei [26,27]; a surface roughness of $0.479 \mathrm{~nm}$ was obtained. Based on these results, a growth model is proposed to elucidate the different morphologies with the substrates featuring different misorientations.

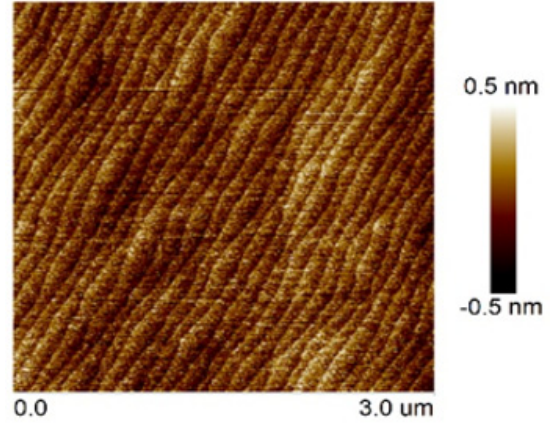

(a)

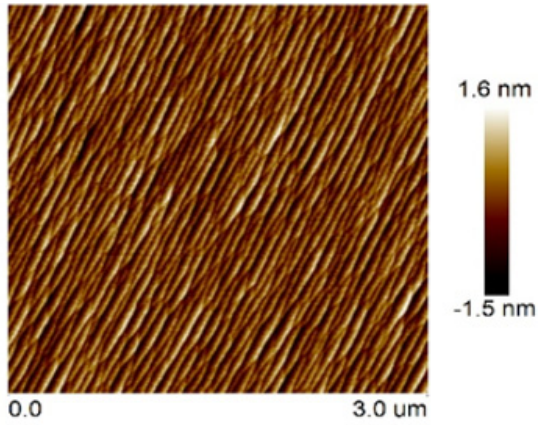

(b)

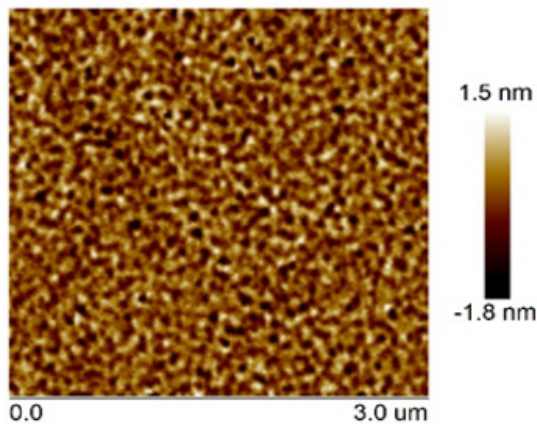

(c)

Figure 4. AFM images of InGaAs/GaAsP QWs in a $3 \times 3 \mu \mathrm{m}^{2}$ scan area with different misoriented substrates: (a) $0^{\circ}$, (b) $2^{\circ}$, and (c) $15^{\circ}$.

Figure 5 illustrates a surface on a substrate that is composed of steps and terraces. The growth condition in this scenario is presumed to involve surface coverage of the misoriented substrate with As atoms, because of the high V/III ratio ( 150). Two dangling bonds are present on the terrace and three dangling bonds are at the kinks of the terrace edges. The incorporation probability of group III atoms into step kinks is presumed to be higher than that on the terraces. Upon reaching the growing surface, the group III species preferentially adhere to the step and kink sites on the terrace edge. This results in a step flow growth mode. The width of the terrace is known to decrease with increasing substrate misorientation, owing to the high density of growth steps on the tilted substrates [28]. 

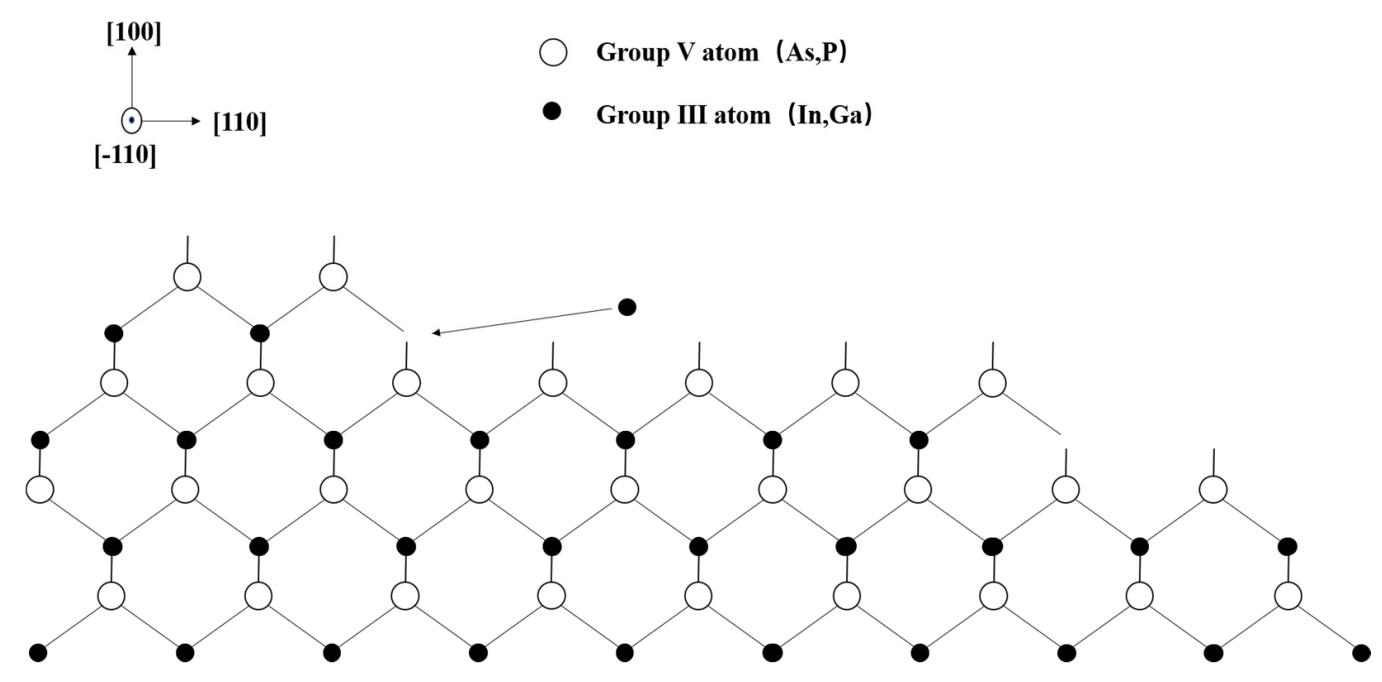

Figure 5. Schematic illustration of the growth process.

The disparity in the samples from the $0^{\circ}$ to the $2^{\circ}$ substrate was possibly caused by the inequality of diffusion lengths of the In and Ga cations for the growth of InGaAs. Ga cations possess smaller diffusion lengths than those of In; therefore, In atoms are likely to be mobile enough to incorporate at the step edges of the $2^{\circ}$ substrate. The bonds in the kink sites are occupied with In cations, and therefore, Ga atoms tend to incorporate at the flat terrace [29]. If this occurs, a severe compositional nonuniformity can arise owing to a "step-induced" clustering of In atoms, which can lead to nonuniform components and the formation of local energy level states, and partial strain relaxation occurs with the formation of in clusters. This modulation, or clustering, did not occur in the $0^{\circ}$ substrate due to the absence of a high density of step edges. As for $15^{\circ}$ sample the formation of randomly positioned growth nuclei and the subsequent local strain relaxation at the nuclear locations could occur owing to the large degree of misorientation, resulting in high strain relaxation and the formation of island.

To study the optical characteristics of the InGaAs/GaAsP QWs on different substrate orientations, temperature-dependent photoluminescence analysis was performed. Figure 6 shows the temperature-dependent PL spectra of three samples. For the $0^{\circ}$ and $15^{\circ}$ samples, it can be seen that the PL intensity decreased and the PL peak wavelength had a red-shift with increasing temperature. But the peak position of the $15^{\circ}$ sample reached $1206 \mathrm{~nm}$ at room temperature and its extremely high FWHM and relatively low intensity indicate the PL characteristics of self-assembled quantum dots. The results are consistent with the AFM results shown in Figure 4c. However, the $2^{\circ}$ sample exhibited an anomalous blue shift tendency of PL peak wavelength in the temperature range from $40 \mathrm{~K}$ to $85 \mathrm{~K}$; the reason is discussed in detail below.

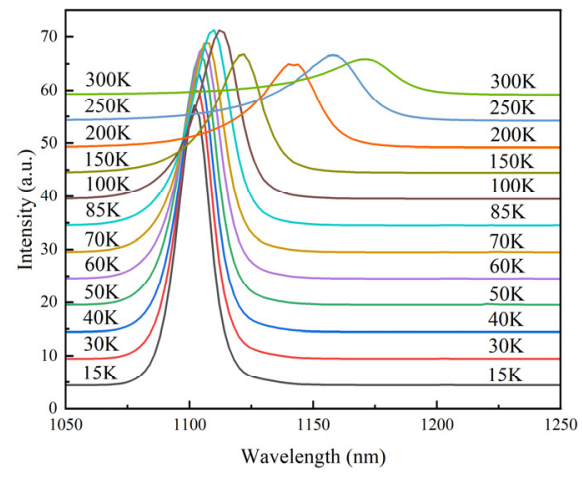

(a)

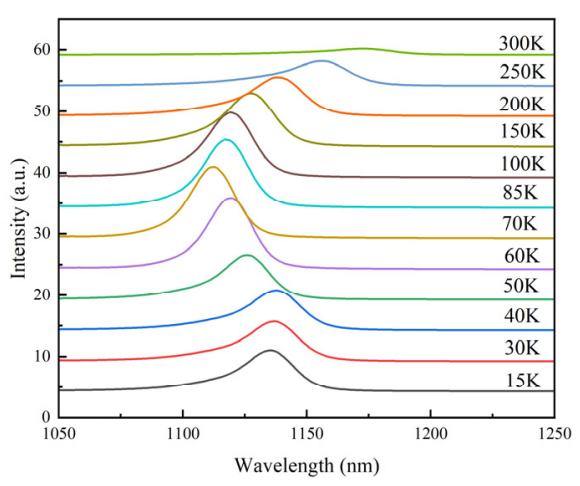

(b)

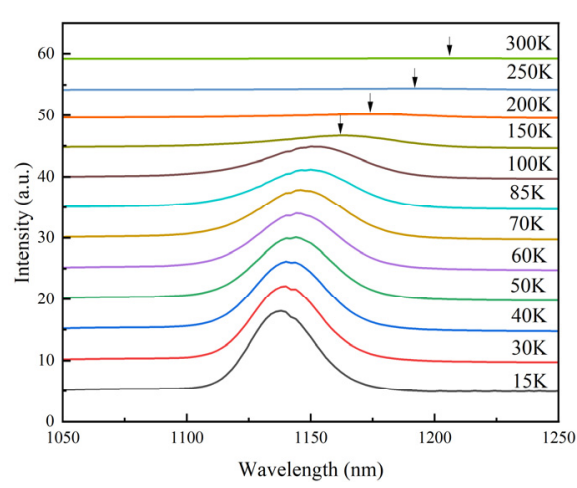

(c)

Figure 6. Temperature-dependent of PL spectra for InGaAs/GaAsP QWs on (a) $0^{\circ}$, (b) $2^{\circ}$, and (c) $15^{\circ}$ misoriented substrates. 
Figure 7 shows the temperature dependence of the PL peak energy of the three samples. The PL peak position of the $0^{\circ}$ sample shifted toward lower energies as the temperature increased over the entire range; this typical behavior can be well fitted using the Varshni empirical formula [30]:

$$
E_{g}(T)=E_{g}(0)-\alpha T^{2} /(\beta+T),
$$

where $E_{g}(0)$ is the energy gap between nominal subband edges at $0 \mathrm{~K}$, and $\alpha$ and $\beta$ are the Varshni equation parameters. The optimizing parameters, $\alpha$ and $\beta$, obtained from optimal fits of the QW data are listed in Table 1.

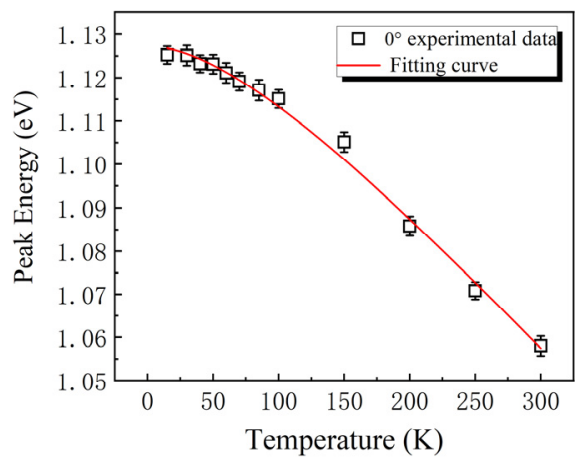

(a)

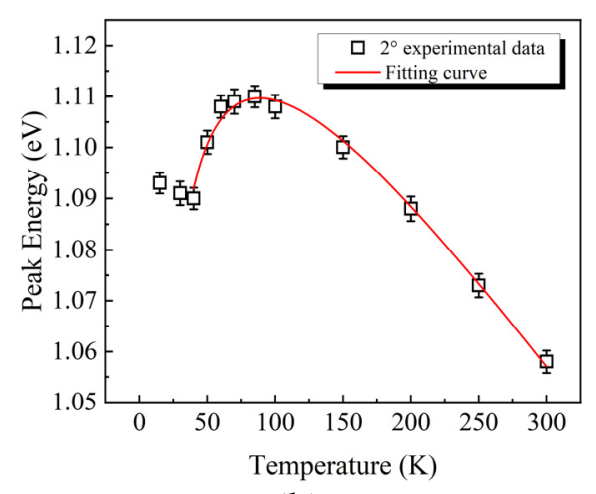

(b)

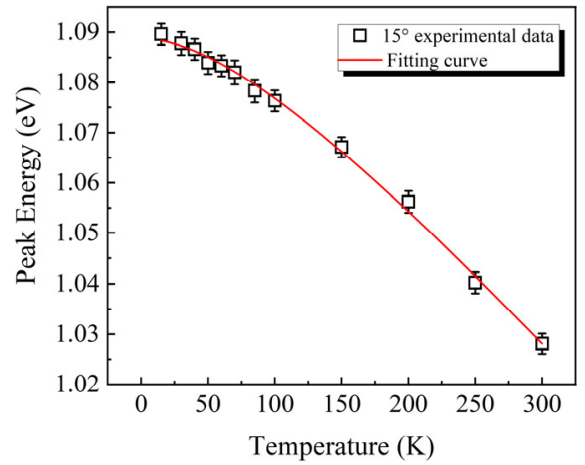

(c)

Figure 7. Temperature-dependent peak energies of the InGaAs/GaAsP QWs on (a) $0^{\circ}$, (b) $2^{\circ}$, and (c) $15^{\circ}$-misoriented substrates.

Table 1. Fitting parameters, $\alpha, \beta$, and $\sigma$, for the differently misoriented substrates.

\begin{tabular}{ccccc}
\hline Sample & $\boldsymbol{E}_{\mathbf{g}}(\mathbf{0})(\mathbf{e V})$ & $\boldsymbol{\alpha}(\mathbf{e V} / \mathbf{K})$ & $\boldsymbol{\beta}(\mathbf{K})$ & $\sigma(\mathbf{m e V})$ \\
\hline $0^{\circ}$ & 1.127 & $3.49 \times 10^{-4}$ & 150 & \\
$2^{\circ}$ & 1.153 & $4.03 \times 10^{-4}$ & 109 & 14.7 \\
$15^{\circ}$ & 1.089 & $2.84 \times 10^{-4}$ & 120 & \\
\hline
\end{tabular}

The peak energies of systems with the $0^{\circ}$ and $15^{\circ}$ substrates can be well fitted using Equation (5); however, the data corresponding to the $2^{\circ}$ sample cannot be fitted using the Varshni empirical formula in the low-temperature range $(\mathrm{T}<60 \mathrm{~K})$. An anomalous band gap evolution in the form of an S-shaped (redshift-blueshift-redshift) PL peak energy was observed at low temperatures. This abnormal behavior may be attributed to the localization effect caused by composition fluctuation [31-35]. Eliseev et al. amended the Varshni empirical equation using band-tail states to fit this type of experimental data as follows [36]:

$$
E_{g}(T)=E_{g}(0)-\alpha T^{2} /(\beta+T)-\sigma^{2} / k_{B} T,
$$

where $k_{B}$ is the Boltzmann constant and $\sigma$ represents the degree of the localization effect. The fitting parameters are listed in Table 1.

Figure $7 \mathrm{~b}$ indicates that the data representing the $2^{\circ}$ substrate can be adequately fitted in the $60-300 \mathrm{~K}$ temperature region. However, the aforementioned empirical models cannot accurately describe the temperature dependence of the peak energy in the InGaAs/GaAsP QW with a $2^{\circ}$ substrate at temperatures below $60 \mathrm{~K}$; the PL peak of the $2^{\circ}$ substrate exhibited a redshift as the temperature increased from 15 to $40 \mathrm{~K}$. The S-shaped variation over the entire temperature range occurred because of the existence of different localization potentials $[37,38]$. A possible explanation for the S-shaped behavior of the peak energy is illustrated in Figure 8. 


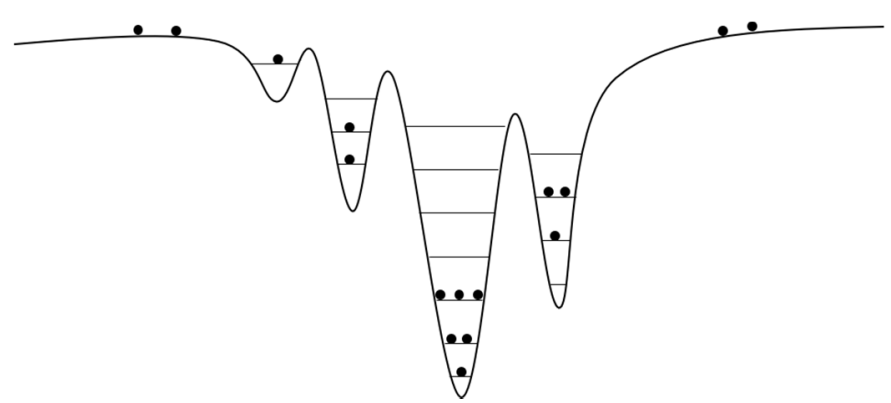

(a)

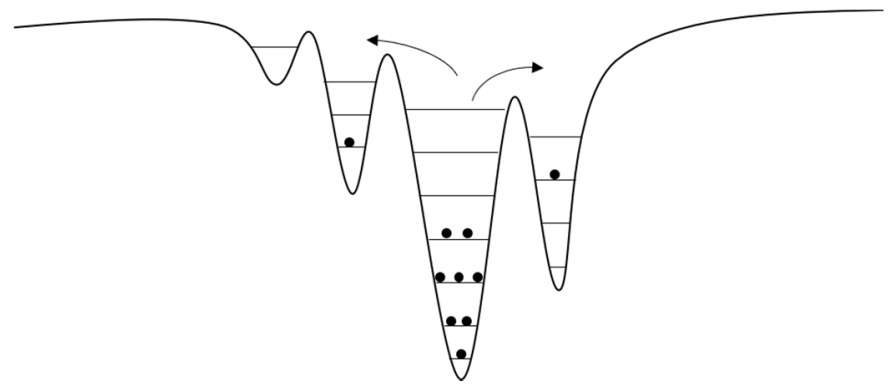

(c)

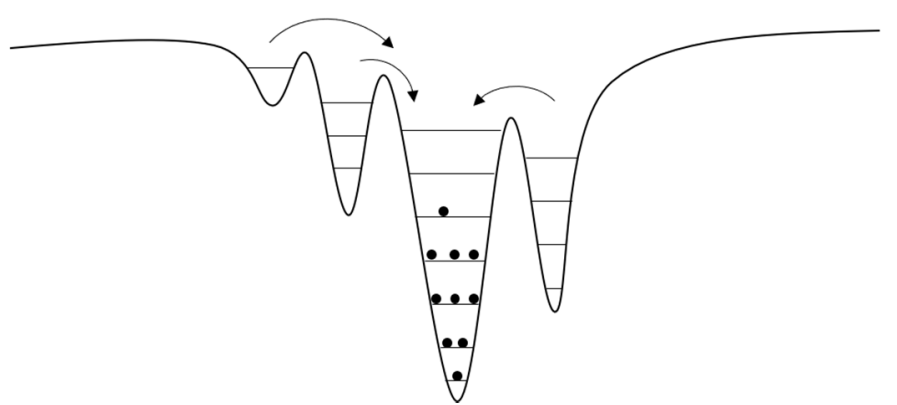

(b)

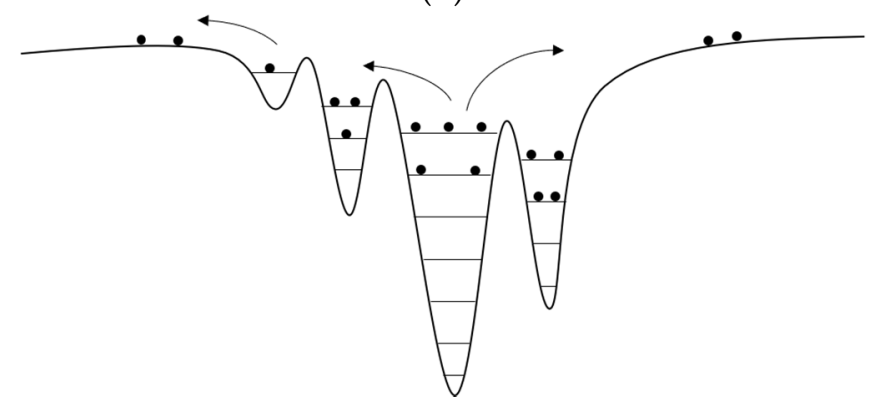

(d)

Figure 8. Schematic diagrams illustrating the possible mechanism of the S-shaped temperature-dependent PL peak energy. (a) At the lowest temperature, carriers exist in all possible potential minimums. (b) At a slightly higher temperature, carriers relax to the deepest potentials. (c) As the temperature continues to rise, carriers redistribute to higher energies. (d) As the temperature rises very high, most carriers escape from the localization potentials.

At low temperatures, carriers are freely distributed throughout the QW layer (Figure 8a). With increasing temperatures, the weakly localized carriers are thermally activated and have a greater chance to relax to the deep localized states (Figure 8b); this results in a red shift in the PL peak energy. A further increase in the temperature leads to the carriers in the deep localized states obtaining sufficient energy to repopulate the shallow localized states (Figure 8c), which produces a blueshift in the emission peak energy. As the temperature continues to rise, the thermal carriers escape from the localized states into the barrier states and become free carriers (Figure 8d); at even higher temperatures, the peak energy exhibited redshifts owing to the shrinkage of the temperature-induced band gap upon thermal activation and delocalization of the carriers [39].

Typically, two factors are known to affect the PL linewidth of the InGaAs/GaAsP QWs, one is inhomogeneous broadening which is primarily determined by fluctuations of circumstance, for example, interface roughness, composition variation, and crystal disorder. The other one is homogeneous which is closely related to temperature and is primarily affected by the interaction between electrons and phonons [40,41].

Figure 9 shows the behavior of the FWHM with respect to temperature. Inhomogeneous broadening and exciton interactions with phonons are considered. The trends of FWHM conform to the following expression [42]:

$$
\Gamma(T)=\Gamma_{0}+a T+\gamma /\left[\left(\exp \left(E_{L O} / k_{B} T\right)-1\right],\right.
$$

where $\Gamma(T)$ represents the FWHM of the photoluminescence spectra, $\Gamma_{0}$ represents the inhomogeneous contribution to the FWHM that is related to the interface roughness and crystal disorder, $a$ is a parameter representing the acoustic phonon scattering strength, $\gamma$ is a parameter that is related to the exciton-phonon coupling, and $E_{L O}$ is the longitudinal optical phonon energy of QW layer. The experimental data of the three samples were fitted using Equation (7) and shown in Figure 9; the fitted parameters are listed in Table 2. The value of $\Gamma_{0}$ is noted to increase with increasing misorientation, which indicates that the interface roughness and alloy disorder increased as the substrate misorientation increased. 
A higher value of $E_{L O}$ is known to indicate a larger strain in the epitaxial layer [13,42]. The highest $E_{L O}$ value corresponded to the $0^{\circ}$ sample and indicated the largest strain in this sample compared to those of the others; considerable strain relaxation was noted to occur in the $2^{\circ}$ and $15^{\circ}$ samples, which had also been implied by the Raman scattering results.

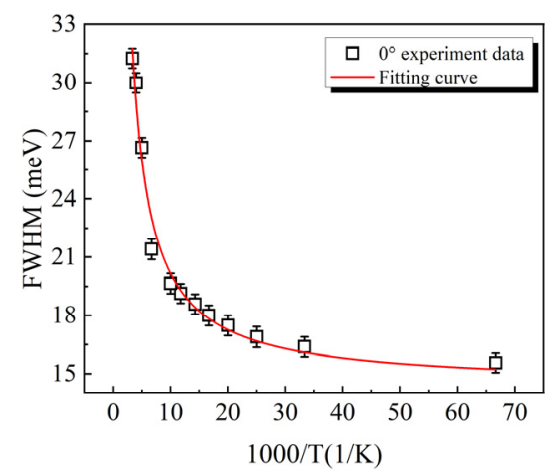

(a)

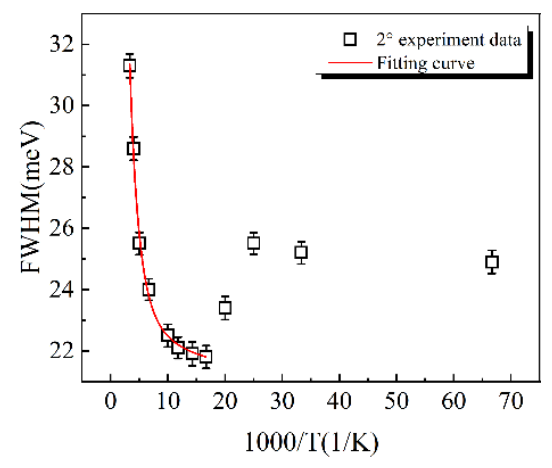

(b)

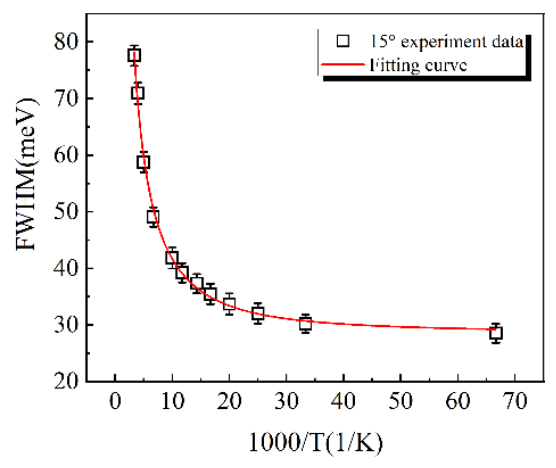

(c)

Figure 9. PL full width at half maximum (FWHM) as a function of 1000/T of the InGaAs/GaAsP QWs on substrates misoriented by (a) $0^{\circ}$, (b) $2^{\circ}$, and (c) $15^{\circ}$. The fitting curves of the FWHM data of the PL spectra are predictions based on the exciton-optical phonon coupling model.

Table 2. FWHM-fitting parameters for samples with different misoriented substrates.

\begin{tabular}{ccccc}
\hline Sample & $\Gamma_{\mathbf{0}}(\mathrm{meV})$ & $a(\mathrm{meV} / \mathrm{K})$ & $\gamma(\mathrm{meV})$ & $E_{L O}(\mathrm{meV})$ \\
\hline $0^{\circ}$ & 14.36 & 0.058 & 1 & 0.83 \\
$2^{\circ}$ & 20.91 & 0.015 & 43 & 0.05 \\
$15^{\circ}$ & 28.00 & 0.081 & 12 & 0.01 \\
\hline
\end{tabular}

The evolution of FWHM vs. temperature revealed a unique tendency before $70 \mathrm{~K}$ for the $2^{\circ}$ sample. The FWHM increased slowly below $40 \mathrm{~K}$, sharply decreased in the $40-70 \mathrm{~K}$ range, and increased above $70 \mathrm{~K}$. The FWHM trends exhibited a reverse temperaturedependent relationship compared to that of the PL peak energy. The FWHM data for the $2^{\circ}$ sample are plotted against the corresponding peak energies in Figure 10, with the temperature spanning the entire region from 15 to $300 \mathrm{~K}$. The fitting linear curve was obtained by the least square method drawn by the solid red line, a clearly negative linear relationship can be observed between them, which indicates that the evolutions of peak energy and FWHM of QW with temperature obey a similar or associated mechanism [43].

At low temperature $(<40 \mathrm{~K})$, carriers are thermally activated upon an increase in the temperature and have a significant opportunity to transit to deeper localization potentials; therefore, the range of energy levels of the carrier distribution widens, which leads to an increment in the FWHM. As the temperature increases to a critical level, the carriers obtain sufficient energy to enable their delocalization. The decrease in FWHM in the temperature range of $40-70 \mathrm{~K}$ was due to the process of carrier escape from the located states. The increment in FWHM at temperatures above $70 \mathrm{~K}$ presumably occurred because of a combination of the thermalization of carriers and phonon scattering caused by the increase in temperature. It is worth noting that the variations of PL peak position and FWHM of the $15^{\circ}$ sample were not similar to the $2^{\circ}$ sample. In addition, the value of the PL peak and FWHM of the $15^{\circ}$ sample were much higher than the $0^{\circ}$ and $2^{\circ}$ samples, this is because large misorientations yield substantial strain relief and random quantum dots can form, therefore the luminescence characteristics are dominated by quantum dots. 


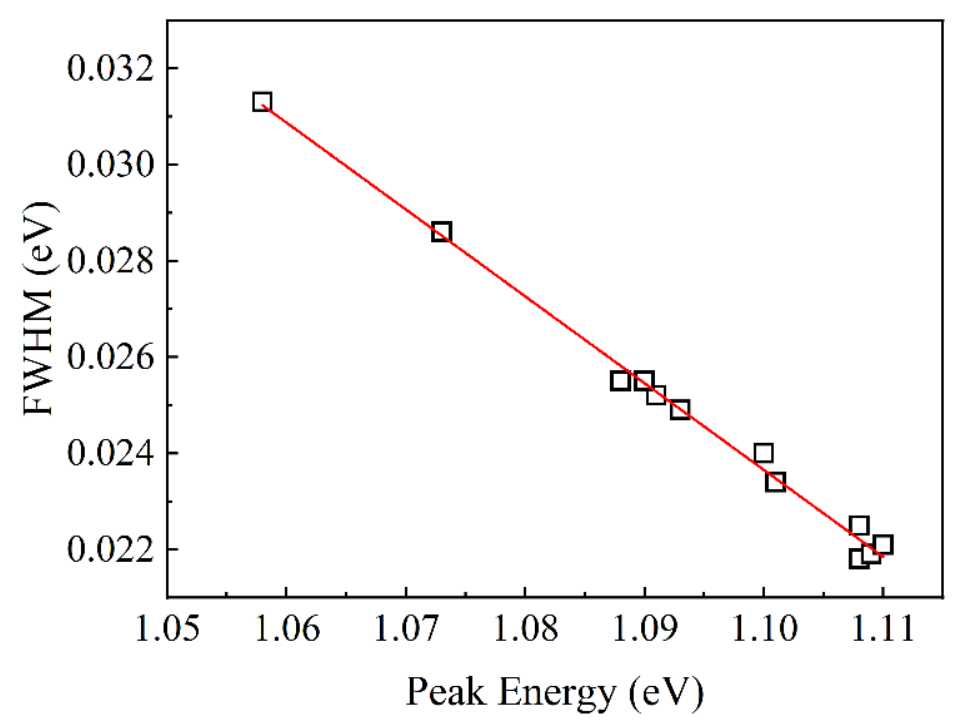

Figure 10. Relationship between photon energy and FWHM for the $2^{\circ}$ sample. The red solid line represents the curve fit to the presented data.

The temperature-dependent PL intensity data can be fit using the Arrhenius equation shown below to study the mechanism of PL quenching with increasing temperatures [44]:

$$
I(T) \propto 1 /\left(1+\sum_{i} C_{i} \exp \left(-E_{i} / k_{B} T\right)\right) .
$$

$I(T)$ represents the integrated PL intensity at temperature $T, C_{i}$ represent the factors related to the densities of nonradiative recombination centers, and $E_{i}$ represent the activation energies of the relevant nonradiative recombination centers. Two types of nonradiative recombination channels have been proposed for the quenching mechanism of PL intensities in epitaxially grown materials. The modified Arrhenius equation used to fit these experimental data can be expressed as [45-47]

$$
I(T) \propto 1 /\left(1+C_{1} \exp \left(-E_{A} / k_{B} T\right)+C_{2} \exp \left(-E_{B} / k_{B} T\right)\right),
$$

where $E_{A}$ and $E_{B}$ are the activation energies of the corresponding nonradiative recombination processes, and $C_{1}$ and $C_{2}$ are two constants that are related to the number of nonradiative recombination centers in the QWs. The modified Arrhenius equation provides excellent fits for the integrated PL intensity data corresponding to the $0^{\circ}$ and $15^{\circ}$ samples and for data obtained at temperatures above $60 \mathrm{~K}$ for the $2^{\circ}$ sample, as shown by the red lines in Figure 11. The parameters used to obtain the optimal fits are listed in Table 3.

Two different nonradiative recombination processes have been typically described. The first process involves thermally activated recombination in traps that are related to the incorporation of impurities [48,49], whereas the second involves the thermal emission of the carriers out of the located states with an activation energy related to the depth of the located states potential, followed by effective nonradiative recombination [38].

The fitting results revealed that all investigated samples $\left(0^{\circ}, 2^{\circ}\right.$, and $\left.15^{\circ}\right)$ possessed nearly similar values of $E_{A}$ and $C_{1}$. This suggests that the types of impurities in the three samples were similar because of them being grown under identical growth conditions. However, the $E_{B}$ of the $2^{\circ}$ sample was significantly higher than those of the $0^{\circ}$ and $15^{\circ}$ samples, because of the deep localized potential formed by the In-rich cluster during its epitaxial growth. The $E_{B}$ of the $15^{\circ}$ sample was lower than those of the other samples, because the quantum effect of quasi-nanocrystals caused by the severe relaxation of stress during the growth of the $15^{\circ}$ sample and the diffusion of In atoms from the well to the barrier in nanodots reduce the potential barrier [50]. The high $C_{2}$ values of the $2^{\circ}$ and 
$15^{\circ}$ samples indicate the high defect density that was caused by stress relaxation during the growth process.

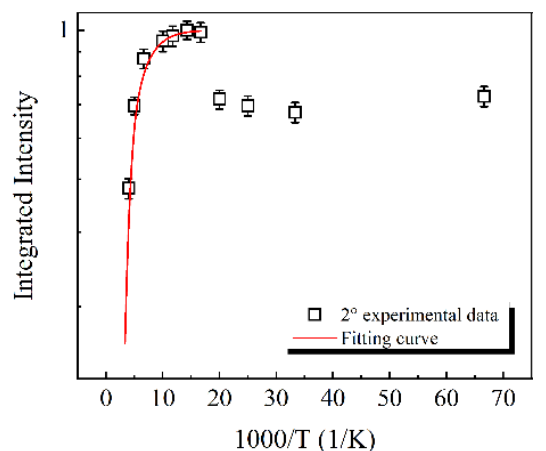

(a)

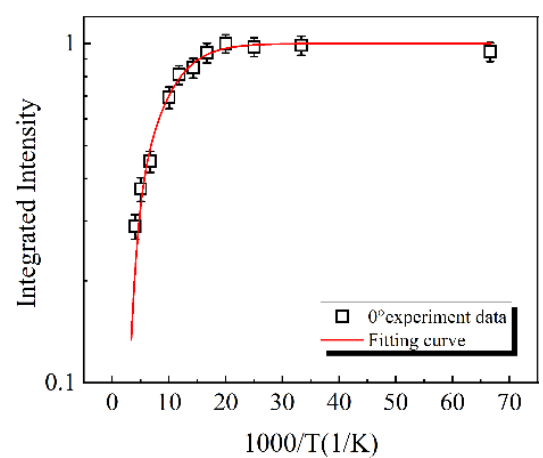

(b)

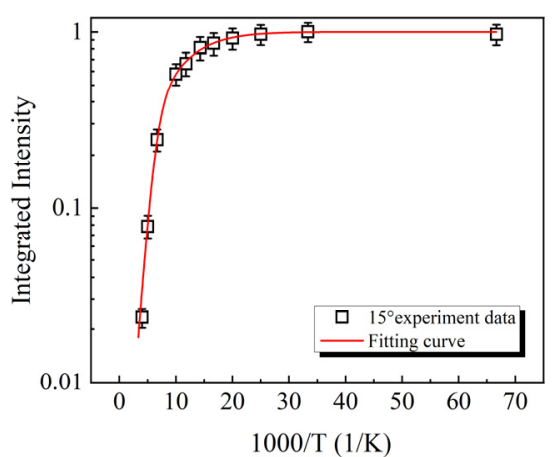

(c)

Figure 11. Temperature dependence of PL integrated intensities of the InGaAs/GaAsP QWs on substrates misoriented by (a) $0^{\circ}$, (b) $2^{\circ}$, and (c) $15^{\circ}$; the data are fitted using the Arrhenius model. An abnormal temperature-dependent PL intensity is observed in the sample with the $2^{\circ}$-misoriented substrate.

Table 3. Parameters obtained by fitting the Arrhenius model for data representing samples with differently misoriented substrates.

\begin{tabular}{ccccc}
\hline Sample & $C_{\mathbf{1}}$ & $\boldsymbol{E}_{\boldsymbol{A}}(\mathbf{m e V})$ & $C_{\mathbf{2}}$ & $\boldsymbol{E}_{\boldsymbol{B}}(\mathrm{meV})$ \\
\hline $0^{\circ}$ & 5.30 & 21.72 & 260 & 106.55 \\
$2^{\circ}$ & 4.01 & 35.25 & 1100 & 148.47 \\
$15^{\circ}$ & 5.96 & 18.72 & 1525 & 87.26 \\
\hline
\end{tabular}

\section{Conclusions}

The effect of substrate misorientation on the structure and optical properties of In-rich InGaAs/GaAs QW structures grown via MOCVD was investigated. Results obtained via XRD and Raman spectroscopy indicated that the strain in the InGaAs/GaAsP decreased monotonically with increasing misorientation. AFM was used to probe the surface morphology and microstructures of the samples, which revealed that with a substrate misorientation of $0^{\circ}$, the growth mode became a step-flow mode and the heterointerface smoothness was degraded as the substrate misorientation increased. The growth mode transformed into three-dimensional growth as the substrate misorientation increased to $15^{\circ}$. Based on these results, the growth of the InGaAs/GaAsP QW nanostructures was modeled from the viewpoint of atomic step motion; a mechanism associated with the accumulation of In on tilted substrates was proposed and verified. The localization potentials formed by the In clusters were primarily caused by the appropriate misoriented substrates and the preferential of $\mathrm{In} / \mathrm{Ga}$ atoms on the terrace to the steps. Based on these results and the parameters related to the temperature-dependent photoluminescence of the samples, the strain relaxation degree of $0^{\circ}$ substrate is the minimum due to the absence of a high density of step edges, a mechanism was proposed for the S-shaped temperature dependence of the peak energy and FWHM of the $2^{\circ}$ sample. Partial strain relaxation occurs with the formation of in clusters owing to the relatively narrow steps, when the substrate misorientation increases to $15^{\circ}$, the formation of randomly positioned growth nuclei yield substantial strain relaxation.

Author Contributions: Conceptualization, Z.L. and Y.Z. (Yugang Zeng); methodology, Z.L. and Y.Z. (Yinli Zhou); software, Z.L.; validation, Y.N., Y.Z. (Yugang Zeng) and Y.S.; formal analysis, J.Z.; investigation, Z.L.; resources, Y.N.; data curation, Y.Z. (Yugang Zeng); writing—original draft preparation, Z.L.; writing - review and editing, Y.Z. (Yugang Zeng) and Y.S.; visualization, Y.S. and L.Q.; supervision, Y.N.; project administration, Y.N. and L.W.; funding acquisition, Y.S. and L.Q. All authors have read and agreed to the published version of the manuscript. 
Funding: This research was funded by National Natural Science Foundation of China (NSFC) (61904179, 62090060, 61727822, 61991433, 61604151, 11874353, 61935009, 61934003, 61674148, 61805236); National Science and Technology Major Project of China (2018YFB2200300, 2016YFE0200700, 2017YFB0503100, 2017YFB0405100, 2018YFB0504600); CAS Projection of instrument development (YJKYYQ20180045); Frontier Science Key Program of the President of the Chinese Academy of Sciences (QYZDY-SSW-JSC006); Key R \& D projects in Guangdong Province (2020B090922003); Equipment pre research (41414060103); Pilot project of CAS (XDB43030302); Science and Technology Development Project of Jilin Province (20200401069GX, 20200401062GX, 20190302042GX).

Institutional Review Board Statement: Not applicable.

Informed Consent Statement: Not applicable.

Data Availability Statement: The data presented in this study are available on request from the corresponding author.

Conflicts of Interest: The authors declare no conflict of interest.

\section{References}

1. Hou, C.-C.; Chen, H.-M.; Zhang, J.-C.; Zhuo, N.; Huang, Y.-Q.; Hogg, R.-A.; Childs, D.T.D.; Ning, J.-Q.; Wang, Z.-G.; Liu, F.-Q.; et al. Near-infrared and mid-infrared semiconductor broadband light emitters. Light-Sci. Appl. 2018, 7, 7. [CrossRef] [PubMed]

2. Nagle, J.; Landesman, J.P.; Larive, M.; Mottet, C.; Bois, P. Indium surface segregation in strained GaInAs quantum wells grown on GaAs by MBE. J. Cryst. Growth 1993, 127, 550-554. [CrossRef]

3. Ma, S.; Wang, Y.; Sodabanlu, H.; Watanabe, K.; Sugiyama, M.; Nakano, Y. Effect of hetero-interfaces on in situ wafer curvature behavior in InGaAs/GaAsP strain-balanced MQW. J. Cryst. Growth 2012, 352, 245-248. [CrossRef]

4. Tansu, N.; Mawst, L.J. High-performance strain-compensated InGaAs-GaAsP-GaAs $(\lambda=1.17 \mu m)$ quantum well diode lasers. IEEE Photonics Technol. Lett. 2001, 13, 179-181. [CrossRef]

5. Pfluegl, C.; Diehl, L.; Tsekoun, A.; Go, R.; Patel, C.K.N.; Wang, X.; Fan, J.; Tanbun-Ek, I.; Capasso, F. Room-temperature continuous-wave operation of long wavelength $(\lambda=9.5 \mu \mathrm{m})$ MOVPE-grown quantum cascade lasers. Electron. Lett. 2007, 43 , 1026-1028. [CrossRef]

6. Choi, W.J.; Dapkus, D.; Jewell, J.J. 1.2- $\mu \mathrm{m}$ GaAsP/InGaAs strain compensated single-quantum-well diode laser on GaAs using metal-organic chemical vapor deposition. IEEE Photonics Technol. Lett. 1999, 11, 1572-1574. [CrossRef]

7. Hou, C.; Zou, Y.; Wang, H.; Wang, X.; Xu, Y.; Wang, Q.; He, Z.; Fan, J.; Shi, L.; Xu, L.; et al. Tailoring strain and lattice relaxation characteristics in InGaAs/GaAsP multiple quantum wells structure with phosphorus doping engineering. J. Alloys Compd. 2019, 770, 517-522. [CrossRef]

8. Dong, H.; Sun, J.; Ma, S.; Liang, J.; Xu, B. Investigation of the growth temperature on indium diffusion in InGaAs/GaAsP multiple quantum wells and photoelectric properties. RSC Adv. 2015, 5, 75211-75217. [CrossRef]

9. Sodabanlu, H.; Wang, Y.; Watanabe, K.; Sugiyama, M.; Nakano, Y. Growth of InGaAs/GaAsP multiple quantum well solar cells on mis-orientated GaAs substrates. J. Appl. Phys. 2014, 115, 233104. [CrossRef]

10. Lin, T.; Lin, N.; Xiong, C.; Zhong, L.; Qi, Q.; Zhao, Y.; Wang, C.; Guo, E.; Liu, S.; Ma, X. Effects of the substrate misorientation on the structural and optoelectronic characteristics of tensile GaInP quantum well laser diode wafer. J. Alloys Compd. 2016, 688, 83-87. [CrossRef]

11. Botha, J.R.; Leitch, A.W.R. Influence of growth interruption on the heterointerface morphology ofInGaAsGaAs strained quantum wells. J. Cryst. Growth 1996, 169, 629-636. [CrossRef]

12. Kwon, Y.H.; Gainer, G.H.; Bidnyk, S.; Cho, Y.H.; Song, J.J.; Hansen, M.; DenBaars, S.P. Structural and optical characteristics of multiple quantum wells with different In compositions. Appl. Phys. Lett. 1999, 75, 2545-2547. [CrossRef]

13. Dong, H.; Sun, J.; Ma, S.; Liang, J.; Lu, T.; Liu, X.; Xu, B. Influence of substrate misorientation on the photoluminescence and structural properties of InGaAs/GaAsP multiple quantum wells. Nanoscale 2016, 8, 6043-6056. [CrossRef] [PubMed]

14. Loudon, R. The Raman effect in crystals. Adv. Phys. 1964, 13, 423-482. [CrossRef]

15. Groenen, J.; Landa, G.; Carles, R.; Pizani, P.S.; Gendry, M. Tensile and compressive strain relief in epilayers grown on InP probed by Raman scattering. J. Appl. Phys. 1997, 82, 803-809. [CrossRef]

16. Emura, S.; Gonda, S.; Matsui, Y.; Hayashi, H. Internal-stress effects on Raman spectra of $\operatorname{In}_{x} G_{1-x}$ As on InP. Phys. Rev. B Condens. Matter 1988, 38, 3280-3286. [CrossRef]

17. Li, J.; Miao, G.; Zhang, Z.; Zeng, Y. Experiments and analysis of the two-step growth of InGaAs on GaAs substrate. Crystengcomm 2015, 17, 5808-5813. [CrossRef]

18. Dong, H.; Sun, J.; Ma, S.; Liang, J.; Lu, T.; Jia, Z.; Liu, X.; Xu, B. Effect of potential barrier height on the carrier transport in InGaAs/GaAsP multi-quantum wells and photoelectric properties of laser diode. PCCP 2016, 18, 6901-6912. [CrossRef]

19. Pistol, M.; Liu, X. Quantum-well structures of direct-band-gap $\mathrm{GaAs}_{1-\mathrm{x}} \mathrm{P}_{\mathrm{x}} / \mathrm{GaAs}$ studied by photoluminescence and Raman spectroscopy. Phys. Rev. B Condens. Matter 1992, 45, 4312-4319. [CrossRef]

20. Pizani, P.S.; Lanciotti, F.; Jasinevicius, R.G.; Duduch, J.G.; Porto, A.V.P. Raman characterization of structural disorder and residual strains in micromachined GaAs. J. Appl. Phys. 2000, 87, 1280-1283. [CrossRef] 
21. Feng, Z.C.; Lin, H.C.; Zhao, J.; Yang, T.R.; Ferguson, I. Surface and optical properties of AlGaInP films grown on GaAs by metalorganic chemical vapor deposition. Thin Solid Films 2006, 498, 167-173. [CrossRef]

22. Feng, Z.C.; Armour, E.; Ferguson, I.; Stall, R.A.; Holden, T.; Malikova, L.; Wan, J.Z.; Pollak, F.H.; Pavlosky, M. Nondestructive assessment of $\mathrm{In}_{0.48}\left(\mathrm{Ga}_{1-} \mathrm{Al}_{\mathrm{x}}\right)$ 0.52 P films grown on GaAs (001) by low pressure metalorganic chemical vapor deposition. J. Appl. Phys. 1999, 85, 3824-3831. [CrossRef]

23. Kubo, M.; Mannoh, M.; Narusawa, T. Raman study of crystalline structure and resonant behavior in $\left(\mathrm{Al}_{\mathrm{x}} \mathrm{Ga}_{1-\mathrm{x}}\right)_{0.5} \mathrm{In}_{0.5} \mathrm{P}$ quaternary alloys. J. Appl. Phys. 1989, 66, 3767-3775. [CrossRef]

24. Kondow, M.; Minagawa, S.; Satoh, S. Raman scattering from AlGaInP. Appl. Phys. Lett. 1987, 51, 2001-2003. [CrossRef]

25. Jia, P.; Qin, L.; Zhang, X.; Zhang, J.; Liu, T.-Y.; Men, Z.-W.; Ning, Y.-Q. Reliability Study of Grating Coupled Semiconductor Laser Based on Raman Spectra Technique. Spectrosc. Spect. Anal. 2016, 36, 1745-1748.

26. Spencer, B.J.; Voorhees, P.W.; Davis, S.H. Morphological instability in epitaxially strained dislocation-free solid films: Linear stability theory. J. Appl. Phys. 1993, 73, 4955-4970. [CrossRef]

27. Snyder, C.W.; Orr, B.G.; Kessler, D.; Sander, L.M. Effect of strain on surface morphology in highly strained InGaAs films. Phys. Rev. Lett. 1991, 66, 3032-3035. [CrossRef]

28. Watanabe, M.; Okajima, M. Dependence of InGaP/InGaAlP heterointerface smoothness on substrate misorientation. J. Appl. Phys. 1996, 80, 3291-3296. [CrossRef]

29. Brown, A.S.; Mishra, U.K.; Henige, J.A.; Delaney, M.J. The effect of InP substrate misorientation on GaInAs-AlInAs interface and alloy quality. J. Appl. Phys. 1988, 64, 3476-33480. [CrossRef]

30. Varshni, Y.P. Temperature dependence of the energy gap in semiconductors. Physica 1967, 34, 149-154. [CrossRef]

31. Chen, X.; Zhao, B.-J.; Ren, Z.-W.; Tong, J.-H.; Wang, X.-F.; Zhuo, X.-J.; Zhang, J.; Li, D.-W.; Yi, H.-X.; Li, S.-T.; et al. Improvement of light extraction efficiency in InGaN/GaN-based light-emitting diodes with a nano-roughened p-GaN surface. J. Mater. Sci. Mater. Electron. 2014, 25, 4200-4205.

32. De, S.; Layek, A.; Raja, A.; Kadir, A.; Gokhale, M.R.; Bhattacharya, A.; Dhar, S.; Chowdhury, A. Two distinct origins of highly localized luminescent centers within InGaN/GaN quantum-well light-emitting diodes. Adv. Funct. Mater. 2011, 21, $3828-3835$. [CrossRef]

33. Wang, Y.; Pei, X.J.; Xing, Z.G.; Guo, L.W.; Jia, H.Q.; Chen, H.; Zhou, J.M. Effects of barrier growth temperature ramp-up time on the photoluminescence of InGaN/GaN quantum wells. J. Appl. Phys. 2007, 101, 033509. [CrossRef]

34. Olaizola, S.M.; Pendlebury, S.T.; O’Neill, J.P.; Mowbray, D.J.; Cullis, A.G.; Skolnick, M.S.; Parbrook, P.J.; Fox, A.M. Influence of GaN barrier growth temperature on the photoluminescence of InGaN/GaN heterostructures. J. Phys. D 2002, 35, 599-603. [CrossRef]

35. Bai, J.; Wang, T.; Sakai, S. Influence of the quantum-well thickness on the radiative recombination of InGaN/GaN quantum well structures. J. Appl. Phys. 2000, 88, 4729-4733. [CrossRef]

36. Eliseev, P.G. The red $\sigma 2 / \mathrm{kT}$ spectral shift in partially disordered semiconductors. J. Appl. Phys. 2003, 93, 5404-5415. [CrossRef]

37. Wang, H.; Ji, Z.; Qu, S.; Wang, G.; Jiang, Y.; Liu, B.; Xu, X.; Mino, H. Influence of excitation power and temperature on photoluminescence in InGaN/GaN multiple quantum wells. Opt. Express 2012, 20, 3932-3940. [CrossRef] [PubMed]

38. Cho, Y.H.; Gainer, G.H.; Fischer, A.J.; Song, J.J.; Keller, S.; Mishra, U.K.; DenBaars, S.P. "S-shaped" temperature-dependent emission shift and carrier dynamics in InGaN/GaN multiple quantum wells. Appl. Phys. Lett. 1998, 73, 1370-1372. [CrossRef]

39. Sarkar, N.; Ghosh, S. The temperature dependence of the band gap shrinkage due to the electron-phonon interaction in $\mathrm{Al}_{\mathrm{x}} \mathrm{Ga}_{1-\mathrm{x}}$ As. J. Phys. Condens. Matter 2006, 18, 1687-1694. [CrossRef]

40. Zhu, T.; Ertekin, E. Resolving anomalous strain effects on two-dimensional phonon flows: The cases of graphene, boron nitride, and planar superlattices. Phys. Rev. B 2015, 91, 205429. [CrossRef]

41. Vashaee, D.; Shakouri, A. Electronic and thermoelectric transport in semiconductor and metallic superlattices. J. Appl. Phys. 2004, 95, 1233-1245. [CrossRef]

42. Rudin, S.; Reinecke, T.L. Temperature-dependent exciton linewidths in semiconductor quantum wells. Phys. Rev. B 1990, 41, 3017-3027. [CrossRef] [PubMed]

43. Song, Y.; Zhang, L.; Zeng, Y.; Chen, Y.; Qin, L.; Zhou, Y.; Luo, Y.; Zhao, H.; Ning, Y.; Wang, L. Temperature-dependent photoluminescence characterization of compressively strained AlGaInAs quantum wells. Mater. Res. Bull. 2019, 115, 196-200. [CrossRef]

44. Deng, Z.; Jiang, Y.; Ma, Z.; Wang, W.; Jia, H.; Zhou, J.; Chen, H. A novel wavelength-adjusting method in InGaN-based light-emitting diodes. Sci. Rep. 2013, 3, 3389. [CrossRef]

45. Fang, Y.; Wang, L.; Sun, Q.; Lu, T.; Deng, Z.; Ma, Z.; Jiang, Y.; Jia, H.; Wang, W.; Zhou, J.; et al. Investigation of temperaturedependent photoluminescence in multi-quantum wells. Sci. Rep. 2015, 5, 12718. [CrossRef] [PubMed]

46. Lu, T.; Ma, Z.; Du, C.; Fang, Y.; Wu, H.; Jiang, Y.; Wang, L.; Dai, L.; Jia, H.; Liu, W.; et al. Temperature-dependent photoluminescence in light-emitting diodes. Sci. Rep. 2014, 4, 6131. [CrossRef]

47. Liu, L.; Wang, L.; Li, D.; Liu, N.; Li, L.; Cao, W.; Yang, W.; Wan, C.; Chen, W.; Du, W.; et al. Influence of indium composition in the prestrained InGaN interlayer on the strain relaxation of InGaN/GaN multiple quantum wells in laser diode structures. J. Appl. Phys. 2011, 109, 073106. [CrossRef]

48. Ding, Y.J.; Guo, C.L.; Li, S.; Khurgin, J.B.; Law, K.K.; Merz, J.L. Continuous-wave photoluminescence excitation spectra of multiple narrow-stepped quantum wells: Evidence for saturation of interface traps. Appl. Phys. Lett. 1992, 60, 154-156. [CrossRef] 
49. Hillmer, H.; Forchel, A.; Sauer, R.; Tu, C.W. Interface-roughness-controlled exciton mobilities in GaAs $/ \mathrm{Al}_{0.37} \mathrm{Ga}_{0.63} \mathrm{As} \mathrm{quantum}$ wells. Phys. Rev. B 1990, 42, 3220-3223. [CrossRef]

50. Weber, S.; Limmer, W.; Thonke, K.; Sauer, R.; Panzlaff, K.; Bacher, G.; Meier, H.P.; Roentgen, P. Thermal carrier emission from a semiconductor quantum well. Phys. Rev. B 1995, 52, 14739-14747. [CrossRef] 